\title{
Do not underestimate anterior prostate cancer
}

\author{
Sarka Kudlackova ${ }^{a}$, Daniela Kurfurstova ${ }^{b}$, Milan Kral ${ }^{a}$, Frantisek Hruska ${ }^{a}$, Ales Vidlar ${ }^{a}$, Vladimir Student ${ }^{a}$
}

\begin{abstract}
Aims. With the introduction of magnetic resonance imaging in the diagnosis of prostate cancer and its use in targeted prostate biopsy, an increased incidence of anterior-predominant prostate cancer (APC) has been observed.

Methods. We enrolled 200 patients who underwent radical prostatectomy at our department between 12/2017 and 04/2019. We evaluated tumour location in the individual segments of the prostate, index tumour location and volume, and compared the postoperative stage, Gleason score, grade group (GG), and the presence of extraprostatic extension (EPE) in APC and posterior prostate cancer (PPC). We assessed the rate of MRI scans prior to prostate surgery as well as the influence of family history and PSA on the presence of APC.

Results. We found a significantly higher rate of anterior tumours than previously reported (37\%) and confirmed that these tumours are diagnosed with a significantly larger index tumour volume $(P=0.003)$. We also showed that a mere $6.76 \%$ of APCs were low-risk tumours not requiring radical treatment. Furthermore, anterior tumours were found significantly more often $(P=0.001)$ in patients who underwent preoperative MRI.

No differences were observed between PSA values, family history, presence of EPE, or locally advanced disease in APC vs. PPC.

Conclusions. The frequency of anterior tumours is higher than previously thought, and they include tumours requiring radical treatment. When these tumours are neglected, it may lead to patient undertreatment with impact on their life prognosis. Thus, we consider the use of MRI-targeted prostate biopsy to be a necessity both for ruling out APC in the case of repeatedly negative prostate biopsies and, in particular, before patient inclusion in active surveillance.
\end{abstract}

Key words: anterior prostate cancer, prostate biopsy, MRI, targeted biopsy

Received: August 9, 2020; Revised: November 6, 2020; Accepted: November 10, 2020; Available online: November, 26, 2020 https://doi.org/10.5507/bp.2020.054

(c) 2021 The Authors; https://creativecommons.org/licenses/by/4.0/

${ }^{a}$ Department of Urology, Faculty of Medicine and Dentistry, Palacky University Olomouc and University Hospital Olomouc, Czech Republic ${ }^{b}$ Department of Clinical and Molecular Pathology, Faculty of Medicine and Dentistry, Palacky University Olomouc, Czech Republic Corresponding author: Daniela Kurfurstova, e-mail: daniela.kurfurstova@seznam.cz

\section{INTRODUCTION}

Generally, the predominant location of prostate cancer in the peripheral zone (PPC - posterior prostate cancer) is well known. Anterior prostate cancer (APC) is defined as a tumour located above the urethra and it contains periurethral tissues, anterior horns of the peripheral zone (APZ), transition zone (TZ), and anterior fibromuscular stroma (AFMS) (Fig. 1). McNeal cited Lowsley's 1912 observation that prostate cancers arose from the peripheral part of the gland ${ }^{1}$. Some $15-25 \%$ of cases are reported to occur in the anterior part of the prostate, but the diagnosis is difficult $\mathrm{t}^{1-7}$. Furthermore, anterior tumours have been reported to be less aggressive and less often spread beyond the prostate ${ }^{8}$. With the introduction of new imaging techniques (MRI, PET CT), it is becoming evident that anterior tumours are more frequent and that they include ones that are clinically significant and tend to be diagnosed with delay. Since the introduction of new imaging techniques and the use of targeted biopsy even in the transition zone and anterior fibromuscular area (TZ and AFMS), the number of patients diagnosed with a tumour with a predilection in the anterior zone has been increasing. This results in an increasing number of these tumours in radical prostatectomy specimens. As radical prostatectomy is indicated only in patients with a histologically confirmed carcinoma, it necessarily results in selection bias as those with an anterior tumour may not be diagnosed in this manner ${ }^{9}$. In other words, patients with an anterior tumour do not undergo radical prostatectomy and, thus, these prostates are not examined and included in the cohort evaluated for tumour location. Data on tumour location in the individual segments of the prostate obtained from radical prostatectomies are then necessarily influenced by this fact.

\section{MATERIAL AND METHODS}

\section{Study cohort}

Between 12/2017 and 04/2019, a cohort of 200 consecutive patients were evaluated who underwent roboticassisted radical prostatectomy at our department and whose histological specimens were assessed by a single pathologist. Of these, $67.5 \%$ were referred from another institution and $32.5 \%$ were diagnosed at our department. Magnetic resonance imaging prior to surgery was performed in $24.5 \%$ of the patients. The mean age of the patients was 65 years, the mean PSA was $8.12 \mathrm{ng} / \mathrm{mL}$, and the mean prostate size was $50 \mathrm{~mL}$. A positive family history was found in $10.5 \%$ of the patients. Characteristics of the study cohort are listed in Table 1. 


\section{Histological processing}

Following radical prostatectomy, the prostate tissue was fixed in $10 \%$ formalin for $24 \mathrm{~h}$ and subsequently processed completely using the method of whole-mount sections. Tissue sections with a thickness of $3 \mu \mathrm{m}$ were stained with haematoxylin-eosin and evaluated by a single pathologist with extensive experience in diagnosing prostate cancer. All carcinoma foci were labelled on the specimens. The three largest of them were measured and drawn in a diagram used in the PIRADS v2 classification, with the largest focus labelled as index tumour.

\section{Statistics (data analysis)}

In this study, clinical and pathologic features were presented as quantiles (median, range) or frequencies. Continuous variables were compared by the MannWhitney test. Categorical variables were tested for independence by Fisher's exact test. A boxplot and/or a barplot were used for graphic presentation. The level of significance was set at 5\% for all statistical tests. All analyses were performed using the statistical software STATISTICA, version 13 (Statsoft, Inc., USA).

We assessed the location of 1-3 largest foci and whether there was a single focus or the tumours were multifocal. We mapped all tumour foci from 200 serially sectioned radical prostatectomy specimens. The volume and anatomic location of each tumour focus were determined. Cancer locations were reported according to an adapted scheme as described by Barentz (Synopsis of PIRADS2). We determined the proportion of individual prostate segments involved by tumour. Subsequently, index tumour location, i.e. the largest focus (anterior vs. posterior), was assessed only. A tumour was labelled as anterior when it was completely or largely in the portion of the prostate located anterior to the urethra. For the largest focus, its volume was calculated from three dimensions using rotational ellipsoid formula. The volumes of anterior and posterior index tumours were compared. For the largest focus, the Gleason score and ISUP grade group were determined ${ }^{10}$. We compared anterior prostate cancer and posterior prostate cancer stratified into three risk groups

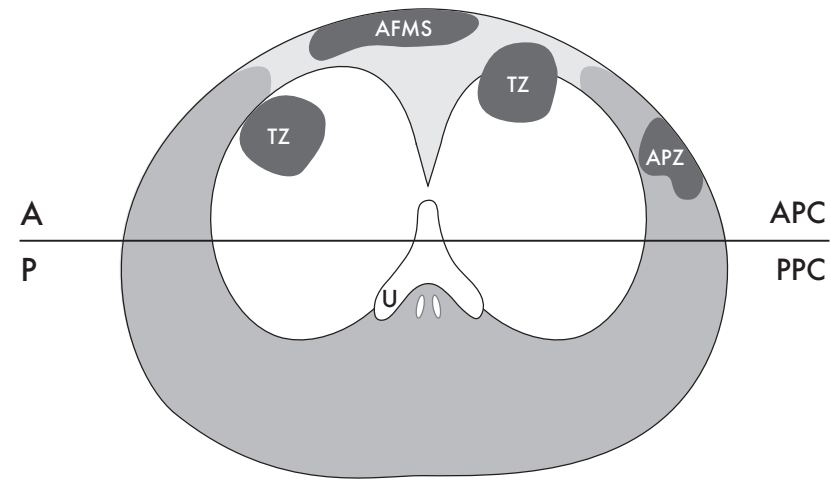

Fig. 1. Anterior part is defined as area anterior to prostatic urethra.

APC - anterior prostate cancer, AFMS - anterior fibromuscular stroma, PPC - posterior prostate cancer, TZ - transition zone, APZ - anterior horns of the peripheral zone. according to D'Amico risk criteria ${ }^{11}$. We also evaluated the occurrence of anterior tumours in patients who had undergone preoperative MRI as well as the effect of family history and PSA levels on the presence of anterior tumour of the prostate.

\section{RESULTS}

A single-focus tumour was identified in $25 \%$ and a multifocal tumour was found in $75 \%$. When the presence of all tumour foci in the individual segments of the prostate was assessed, there was no difference between anterior and posterior tumours. In fact, the tumour rate was higher in the anterior segments: $52.5 \%$ vs. $47.5 \%$ (Fig. 2).

Anterior index tumour and posterior index tumour were found in $74(37 \%)$ and 126 (63\%) of 200 patients, respectively (Fig. 3). Anterior index tumours were shown to have significantly larger volumes than posterior ones $(P=0.003)$.

When comparing the postoperative stage according to ISUP GG, no difference was shown between anterior and posterior tumours in the low- and moderate-risk groups. In the high-risk group, there were significantly more posterior tumours $(P=0.004)$. In the patients who underwent MRI, anterior tumours were more frequent (37.84\% vs. $16.67 \%, P=0.001$ ).

When the absolute PSA level was compared, no difference was found between these two groups of tumours (median $6.09 \mathrm{ng} / \mathrm{mL}$ in anterior vs. $5.94 \mathrm{ng} / \mathrm{mL}$ in posterior ones). Furthermore, no effect of a positive family history on tumour location $(12.1 \%$ in anterior vs. $9.5 \%$ in posterior ones, $P=0.64$ ) and no difference between the occurrence of extraprostatic extension or PSM in APC vs. PPC was shown (Table 1).

\section{DISCUSSION}

The diagnosis of prostate cancer is still based only on histological examination of prostate biopsy samples, transurethral resection samples or radical prostatectomy specimens. Over the years, the protocol of prostate biopsy has changed with an aim to increase the detection rate of prostate cancer and reduce the morbidity rate associated with the procedure. The originally used sextant biopsy was modified, based on systematic reviews, into multiple systematic biopsy with needle biopsies directed at the peripheral zone and more laterally, so that the maximum core length would be from this part ${ }^{12-14}$. This resulted in an increase in detection rate to $29-56 \%$ (ref. ${ }^{14}$ ). These studies then led to the conclusion that the carcinoma occurred with a predilection in the peripheral zone and, if found in the anterior part, the tumour was insignificant. Anterior prostate is routinely undersampled by standard TRUSguided biopsy because anterior biopsies are excluded from standard 12-core template biopsy. If saturation biopsy (more than 18 samples) is performed as part of rebiopsy, the transition zone and anterior part of the prostate are not examined sufficiently ${ }^{14-15}$. The overwhelming majority 

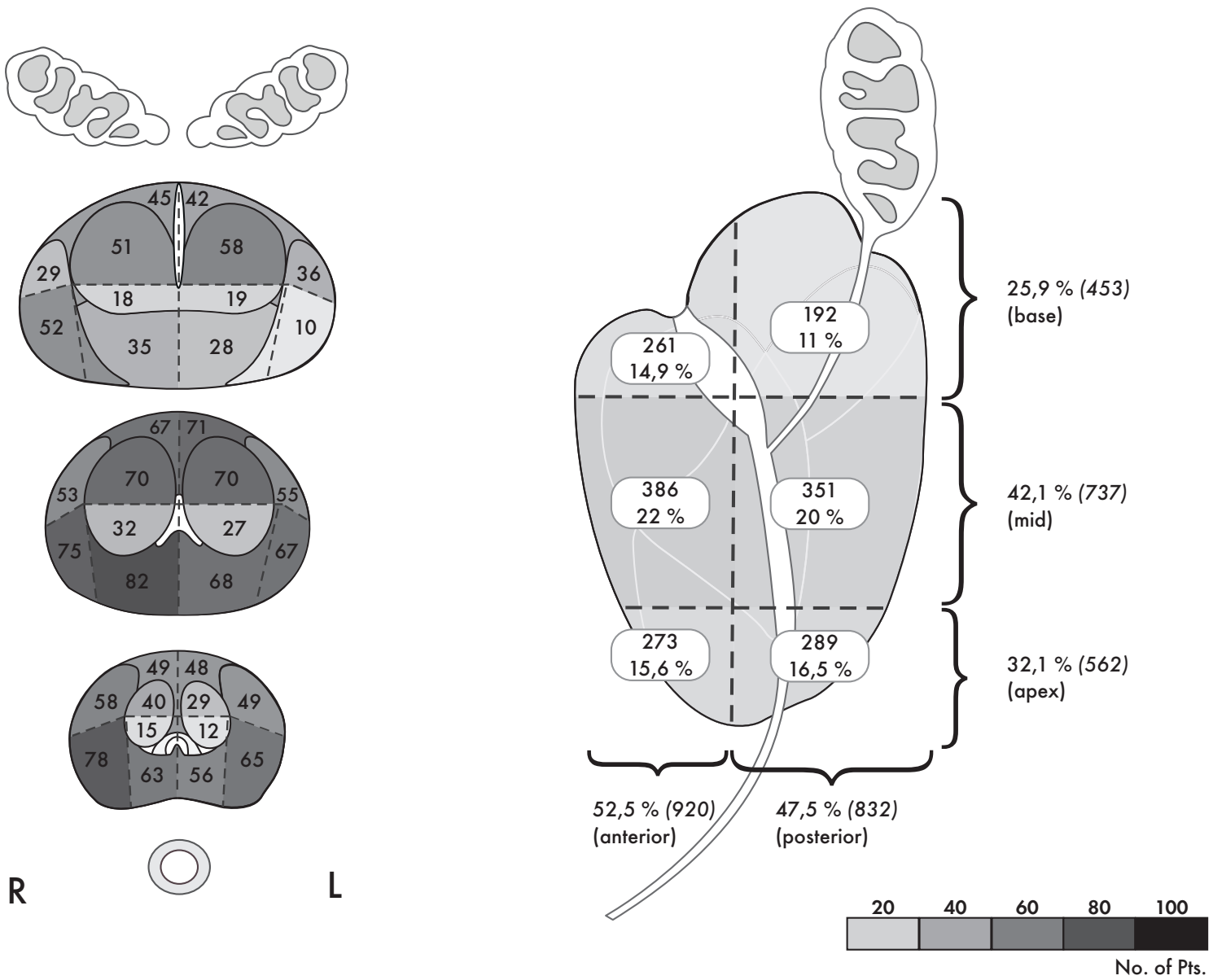

Fig. 2. Number of tumour involvement in the individual segments . According to PIRADS v.2.

of studies on tumour location, including McNeal studies, have been conducted on material obtained from radical prostatectomies ${ }^{2}$. Moreover, these tumours were largely diagnosed with biopsy of the peripheral zone, which meant that only peripheral zone tumours, a certain proportion of transition zone tumours, and anterior tumours with a large volume were thus detected. Only a few studies evaluated tumour location from autopsies or radical cystoprostatectomy material. The ones that did, reported nearly identical occurrence in the anterior vs. peripheral zones. Because of the study design, the majority of findings were tumours with a small volume ${ }^{16-17}$.

With the advent of multiparametric MRI in the diagnosis of prostate cancer, an increased tumour occurrence in the anterior zone has been observed. We have confirmed this finding by evaluating our cohort. With respect to the conclusions of previous publications, we addressed several questions.

1. Does it still hold true that anterior tumours are less frequent? In our cohort, we failed to show a significantly higher occurrence of tumours in the peripheral zone compared to those in the anterior zone. In other words, we can say that anterior tumours are equally frequent.

2. Anterior tumours are diagnosed with a larger tumour volume. Yes, it is true. This suggests that these tu-

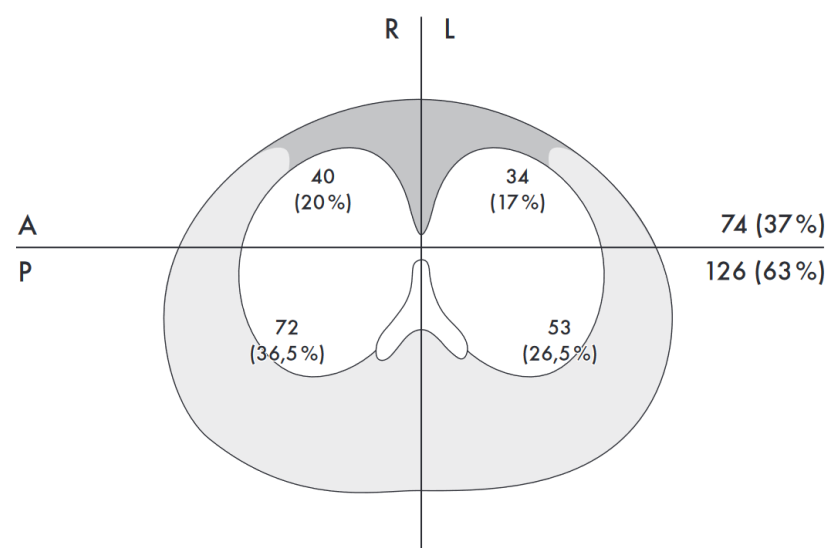

Fig. 3. Location of index tumour in individual quadrates. $\mathrm{A}$ - anterior $\mathrm{P}$ - posterior.

mours are diagnosed later than those in the peripheral zone.

3. Anterior tumours are diagnosed at a higher PSA level. We failed to confirm the assumption that anterior tumours are mostly diagnosed at higher PSA levels. We believe that this has been contributed to by the introduction of magnetic resonance imaging in the rebiopsy strategy, particularly with higher PSA levels ${ }^{18}$.

4. Anterior tumours are less aggressive. This statement may be accepted with regard to the significantly more 
Table 1. Demographic and clinicopathological comparison of anterior vs posterior tumor locations.

\begin{tabular}{|c|c|c|c|c|}
\hline \multirow[b]{2}{*}{ Variable } & \multirow{2}{*}{$\begin{array}{l}\text { Overall } \\
n=200\end{array}$} & \multicolumn{2}{|c|}{ Tumor location } & \multirow[b]{2}{*}{$P$} \\
\hline & & $\begin{array}{c}\text { Posterior } \\
\mathrm{n}=126\end{array}$ & $\begin{array}{c}\text { Anterior } \\
\mathrm{n}=74\end{array}$ & \\
\hline \multicolumn{5}{|l|}{ Age at surgery (year) } \\
\hline Mean (s.d.) & $65(7)$ & $65(7)$ & $66(7)$ & \multirow[t]{2}{*}{0.62} \\
\hline Median (range) & $65(60-70)$ & $65(60-70)$ & $66(60-70)$ & \\
\hline \multicolumn{5}{|l|}{ Pretreatment PSA(ng/Ml) } \\
\hline Mean (s.d.) & $8.13(7.22)$ & $7.40(5.41)$ & $9.36(9.46)$ & \multirow[t]{2}{*}{0.74} \\
\hline Median (range) & $6.03(4.61-8.90)$ & $6.09(4.80-8.30)$ & $5.94(4.50-10.00)$ & \\
\hline \multicolumn{5}{|l|}{ Tumor volume (cc) } \\
\hline Mean (s.d.) & $1.610(2.08)$ & $1.281(1.759)$ & $2.170(2.452)$ & \multirow[t]{2}{*}{0.003} \\
\hline Median (range) & $0.794(0.352-1.809)$ & $0.679(0.283-1.649)$ & $1.102(0.545-2.884)$ & \\
\hline \multicolumn{5}{|l|}{ MRI before treatment } \\
\hline Yes & $49(24.50 \%)$ & $21(16.67 \%)$ & $28(37.84 \%)$ & \multirow[t]{2}{*}{0.001} \\
\hline No & $151(75.50 \%)$ & $105(83.33 \%)$ & $46(62.16 \%)$ & \\
\hline \multicolumn{5}{|l|}{$\mathrm{CaP}$ family history } \\
\hline Yes & $21(10.50 \%)$ & $12(9.52 \%)$ & $9(12.16 \%)$ & \multirow[t]{2}{*}{0.56} \\
\hline No & $179(89.50 \%)$ & $114(90.48 \%)$ & $65(87.84 \%)$ & \\
\hline \multicolumn{5}{|l|}{ Pathological T stage } \\
\hline pT2 & $142(71.00 \%)$ & $83(65.87 \%)$ & $59(79.73 \%)$ & \multirow[t]{2}{*}{0.037} \\
\hline pT3 & $58(29.00 \%)$ & $43(34.13 \%)$ & $15(20.27 \%)$ & \\
\hline \multicolumn{5}{|c|}{ EAU risk group before operation } \\
\hline Low & $110(55.00 \%)$ & $65(51.59 \%)$ & $45(60.81 \%)$ & \multirow{3}{*}{0.22} \\
\hline Intermediate & $76(38.00 \%)$ & $52(41.27 \%)$ & $24(32.43 \%)$ & \\
\hline High & $14(7.00 \%)$ & $9(7.14 \%)$ & $5(6.76 \%)$ & \\
\hline \multicolumn{5}{|l|}{ EAU risk group after operation } \\
\hline Low & $12(6.00 \%)$ & $7(5.56 \%)$ & $5(6.76 \%)$ & \multirow{3}{*}{0.004} \\
\hline Intermediate & $165(82.50 \%)$ & $100(79.37 \%)$ & $65(87.84 \%)$ & \\
\hline High & $23(11.50 \%)$ & $19(15.08 \%)$ & $4(5.41 \%)$ & \\
\hline \multicolumn{5}{|l|}{ PSA group (ng/Ml) } \\
\hline $0-4$ & $32(16.00 \%)$ & $19(15.08 \%)$ & $13(17.57 \%)$ & \multirow{4}{*}{0.11} \\
\hline $4-10$ & $132(66 \%)$ & $89(70.63 \%)$ & $43(58.11 \%)$ & \\
\hline $10-20$ & $26(13.00 \%)$ & $15(11.90 \%)$ & $11(14.86 \%)$ & \\
\hline$>20$ & $10(5.00 \%)$ & $3(2.38 \%)$ & $7(9.46 \%)$ & \\
\hline \multicolumn{5}{|l|}{ Surgical margin status } \\
\hline Positive & $37(18.50 \%)$ & $23(18.25 \%)$ & $14(18.92 \%)$ & \multirow[t]{2}{*}{1.00} \\
\hline Negative & $163(81.50 \%)$ & $103(81.75 \%)$ & $60(81.08 \%)$ & \\
\hline \multicolumn{5}{|l|}{ Primary diagnosis } \\
\hline In our institution & $65(32.50 \%)$ & $23(28.57 \%)$ & $14(39.19 \%)$ & \multirow[t]{2}{*}{0.16} \\
\hline Referred to our institution & $135(67.50 \%)$ & $90(71.43 \%)$ & $45(60.81 \%)$ & \\
\hline
\end{tabular}

Continuous variables were compared with the Wilcoxon rank sum test. Categorical variables were compared using the Fisher exact test.

frequent occurrence of high-risk carcinoma in PPC ( $15.8 \%$ vs. $5.41 \%)$. On the other hand, only $6.76 \%$ of APCs were low-risk tumours not requiring active therapy. Anterior tumours thus deserve the same attention as posterior ones.

Since the introduction of new imaging techniques and targeted biopsies even into the transition and anterior zones, the number of patients diagnosed with a tumour in these locations has been increasing ${ }^{18-21}$ and, as a result the number of anterior prostate cancers in radical prostatectomy specimens has been increasing, too. We can assume that it is selection bias that causes this difference ${ }^{9}$.
Previous series have suggested that anterior tumours are not significant and that, in the vast majority of cases, the index tumour is located in the peripheral zone $\mathrm{e}^{4-19}$. Our results, however, show that there are large tumours that are found in the anterior zone only and, thus, are missed with standard biopsy. As our results suggest, the frequency of anterior tumours is significantly higher compared with the literature (37\% vs. $24.9 \%$ ) (ref. $^{18}$ ). Contrary to previous expectations, however, they are not merely insignificant carcinomas that would not require radical treatment (only $6.76 \%$ of APCs were low-risk tumours). In the past, these patients underwent repeated biopsies, and a proportion of them were diagnosed at a time when their disease was 
advanced or generalized and they could not be offered radical treatment with a curative intent. Referring to our results, we recommend inclusion of targeted prostate biopsy in the standard diagnostic protocol for prostate cancer. Particularly in cases when patient inclusion in an active surveillance protocol is considered, we find it crucial to rule out anterior tumour by MRI-targeted biopsy $^{22}$. Consequently, if a significant anterior tumour is not ruled out, patient undertreatment may occur during active surveillance ${ }^{23-25}$.

\section{CONCLUSION}

With the introduction of MRI-targeted prostate biopsy in the standard diagnostic protocol, an increased occurrence of anterior prostate cancers has been observed. But they are not merely insignificant carcinomas that would not require radical treatment. Our results are of such significance and have such an important impact on the diagnosis and treatment that we consider it necessary to include MRI-targeted prostate biopsy in the standard diagnostic protocol. Anterior tumours should be considered especially in the case of repeatedly negative prostate biopsies and, in particular, before including a patient in active surveillance.

Acknowledgements: This work was supported by IGA2018- 033 grant of the Faculty of Medicine and Dentistry, Palacky University Olomouc.

Author contributions: SK, DK: manuscript writing, literature search, data analysis; MK, FH: literature search, data analysis; AV: editing according to journal requirements; VS: final corrections and critical reading of manuscript. Conflict of interest statement: The authors declare that there are no conflicts of interest regarding the publication of this article.

\section{REFERENCES}

1. McNeal JE, Cancer volume and site of origin of adenocarcinoma in the prostate: relationship to local and distant spread. Hum Pathol 1992;23:258-66.

2. McNeal JE, Haillot O. Patterns of spread of adenocarcinoma in the prostate as related to cancer volume. Prostate 2001;49:48-57.

3. McNeal JE, Redwine EA, Freiha FS, Stamey TA. Zonal distribution of prostatic adenocarcinoma: correlation with histologic pattern and direction of spread. Am J Surg Pathol 1988;12(12):897-906.

4. Al-Ahmadie HA, Tickoo SK, Olgac S, Gopalan A, Scardino PT, Reuter VE, Fine SW. Anterior-predominant prostatic tumors: zone of origin and pathologic outcomes at radical prostatectomy. Am J Surg Pathol 2008;32:229-35.

5. Stamey TA, Donaldson AN, Yemoto CE, McNeal JE, Sözen S, Gill $\mathrm{H}$. Histological and clinical findings in 896 consecutive prostates treated only with radical retropubic prostatectomy: epidemiologic significance of annual ganges. J Urol 1998;160:2412-17.

6. Liu IJ, Macy M, Lai YH, Terris MK. Critical evaluation of the current indications for transition zone biopsies. Urology 2001;57:1117-20.
7. Bott SR, Young MP, Kellett MJ, Parkinson MC. Anterior prostate cancer: is it more difficult to diagnose? BJU Int 2002;89:886-89.

8. Koppie TM, Bianco FJ, Jr, Kuroiwa K, Reuter VE, Guillonneau B, Eastham JA, Scardino PT. The clinical features of anterior prostate cancers. BJU international 2006;98(6):1167-71.

9. Schouten MG, van der Leest M, Pokorny M, Hoogenboom M, Barentz JO, Thompson LC, Fütterer JJ. Why and where do we miss significant prostate cancer. Eur Urol 2017;71:896-903.

10. Epstein Jl, Egevad L, Amin MB, Delahunt B, Srigley JR, Humphrey PA. The 2014 International Society of Urological Pathology (ISUP) consensus conference on Gleason grading of prostatic carcinoma. Am J Surg Pathol 2016;40:244-52.

11. D'Amico AV, Whittington R, Malkowicz SB, Cote M, Schultz D, Chen $\mathrm{MH}$, Tomaszewski JE, Renshaw AA, Wein A, Richie JP. Biochemical outcome after radical prostatectomy or external beam radiation therapy for patients with clinically localized prostate carcinoma in the prostate specific antigen era. Cancer 2002;95(2):281-86.

12. Eichler K, Hempel S, Wilby J, Myers L, Bachmann LM, Kleijnen J. Diagnostic value of systematic biopsy methods in the investigation of prostate cancer: a systematic review. J Urol 2006;175:1605-12.

13. Chen ME, Johnston DA, Tang K, Babaian RJ, Troncoso P. Detailed mapping of prostate carcinoma foci: biopsy strategy implications. Cancer 2000;89(8):1800-9.

14. Meng MV, Franks JH, Presti JC, Jr, Shinohara K. The utility of apical anterior horn biopsies in prostate cancer detection. Urol Oncol 2003;21:361-65.

15. Stewart ChS, Leibovich BC, Weaver AL, Lieber MM Prostate cancer diagnosis using a saturation needle biopsy technique after previous negative sextant biopsies. J Urol 2001;166,86-92.

16. Montie JE, Wood DP, Jr, Pontes JE, Boyett JM, Levin HS. Adenocarcinoma of the prostate in cystoprostatectomy specimens removed for bladder cancer. Cancer 1989;63:381-85.

17. Kabalin JN, McNeal JE, Price HM, Freiha FS, Stamey TA. Unsuspected adenocarcinoma of the prostate in patients undergoing cystoprostatectomy for other causes: incidence, histology and morphometric observations. J Urol 1989;141:1091-94.

18. Teloken PE, Li J, Woods CG, Cohen RJ. The impact of prostate cancer zonal origin on pathological parameters at radical prostatectomy and subsequent biochemical failure. J Urol 2017;198(6):1316-23.

19. Cheng L, Jones TD, Pan CX, Barbarin A, Eble JN, Koch MO. Anatomic distribution and pathologic characterization of small-volume prostate cancer $(<0.5 \mathrm{ml})$ in whole-mount prostatectomy specimens. Mod. Pathol 2005;18(8):1022-26.

20. de Rooij M, Hamoen EH, Witjes JA, Barentsz JO, Rovers MM. Accuracy of magnetic resonance imaging for local staging of prostate cancer: a diagnostic meta-analysis. Eur Urol 2016;70:233-45.

21. Schoots IG, Roobol MJ, Nieboer D, Bangma CH, Steyerberg EW, Hunink MG. Magnetic resonance imaging-targeted biopsy may enhance the diagnostic accuracy of significant prostate cancer detection compared to standard transrectal ultrasound-guided biopsy: a systematic review and meta-analysis. Eur Urol 2015;68:438-50.

22. Glass AS, Pugashetti NB, Dall'Era MA, Evans CP, Yap SA. Utility of anterior zone biopsy in men enrolled in active surveillance for prostate cancer. Clin Genitourin Cancer doi: 10.1016/j.clgc.2017.07.007 Epub 2017 July 14

23. Tosoian JJ, Mamawala M, Epstein Jl, Landis P, Wolf S, Trock BJ, Carter HB. et Intermediate and longer-term outcomes from a prospective active-surveillance program for favorable-risk prostate cancer. J Clin Oncol 2015;33:3379-85.

24. Lawrentschuk N, Haider MA, Daljeet N, Evans A, Toi A, Finelli A, Trachtenberg J, Zlotta A, Fleshner N. Prostatic evasive anterior tumours: the role of magnetic resonance imaging. BJU Int 2010;105:1231-36.

25. Hoeks CM, Barentsz JO, Hambrock T, Yakar D, Somford DM, Heijmink SW, Scheenen TW, Vos PC, Huisman H, van Oort IM, Witjes JA, Heerschap A, Fütterer JJ. Prostate cancer: multiparametric MR imaging for detection, localization, and staging. Radiology 2011;261:4666. 